\title{
Analysis of Wave Power Plant on the Northeast Coast of the Absheron Peninsula
}

\author{
Fuad Mammadov \\ Azerbaijan State Oil and Industry University, Baku, Azerbaijan
}

Email address:

fm.solarpower@gmail.com

\section{To cite this article:}

Fuad Mammadov. Analysis of Wave Power Plant on the Northeast Coast of the Absheron Peninsula. American Journal of Modern Energy. Vol. 3, No. 4, 2017, pp. 84-89. doi: 10.11648/j.ajme.20170304.14

Received: May 11, 2017; Accepted: June 29, 2017; Published: August 9, 2017

\begin{abstract}
The article deals with the study of Wells turbine in accordance with the wave energy potential of the northeastern coast of the Absheron Peninsula. Show a methodical approach to determine the main technical parameters of the turbine Wells. In accordance with the procedure were the main parameters of the Wells turbine, including efficiency and productivity.
\end{abstract}

Keywords: Wave Energy, Wells Turbine, Absheron Peninsula, Caspian Sea Coast

\section{Introduction}

The main renewable energy sources are sea and ocean wave energy having the greatest density in comparison with the rest renewable energy sources [1], [2], [3], [4]. So, if wave period consists of 7-10 seconds, and its amplitude equals to $2 \mathrm{~m}$, in this case average transportable capacity reaches $40-70 \mathrm{~kW}$ per unite of the wave width [5], [6].

The World sea wave energy resources are approximately $10 \mathrm{TJ} /$ year. The most important regions have averagely output level reaches $20-70 \mathrm{~kW} / \mathrm{m}$ and higher, where often and strong storms happen are located at $30-60^{\circ}$ latitude. Also the attractive regions being situated at $\pm 30^{\circ}$ latitude where the wind blows always and the lowest power level is balanced by the most regular waves characterized here.

At present in many countries for determining the huge wave energy potential, study possibilities have been doing to gain effective ways of wave energy to have electricity. The proper projects in Denmark, France, Germany, Greece, The Great Britain, Italy, Portugal, Holland, Sweden and others realized researches by the state support at the Universities within groups, as well as at the industry enterprises [7], [8], [9], [10].

The joint projects and theoretical researches' Opportunities in the international arena are widely realized. Frequently Russia, Indonesia, Iran and Mexico participate at the universities' researches of the other countries within Europe and Asia territory. During discussion of the rising problems, the important role for the ideas exchange and practical results concerns to the international conferences dealing with sea energy conversion ways.

These conferences were held in the UK (1993), Portugal (1995), Greece (1998), Denmark (2000), and Ireland (2003) with the support of the European Commission established in 1986 to monitor and coordinate researches in this field.

The ocean waters' tides and ebbs are considered as the natural phenomenon mostly taking place along the coastlines.

\section{Energy Analysis}

For energy usage the exact requirement is the energy accumulation gained at $25-70 \mathrm{~m}$ depth possessing $1.5-3 \mathrm{~m}$ speed of per each second. Such natural energy production usage is not only achievable, but also a very effective way to generate clean energy from alternative energy source.

In spite of tidal and ebb energy are counted as trustable project, also wave energy offers to access cheaper and cleaner energy. Wave energy conversion to the electricity is widely applied to obtain economical benefits and environmental safety properties by enriching renewable energy sector.

Wind turbines built on the earth give opportunity to utilize the underwater energy sources and technologically show the possibilities because the most modern wind turbines can be easily used to get sea wave energy.

Physic scientists studied the moon gravity influencing on the ocean currents.

The ocean ebb and flow are natural event being easily forecasted for many further. 
This pure alternative energy source impact on any weather conditions or climate change. Thus, the energy storage should be future ideal research object for application. For building and designing the artificial dams to manage specifically tides the usage of innovative technologies aught to aid the ocean energy sector development. The ways forecasted lets ocean waters flow via the gulfs, where water faces with dam barrier, then releases via the special drainage gate to pass into turbine for generating electricity.

The alternative energy source has been perfectly developed in La Rance, France since 1966 at the stations with $240 \mathrm{~mW}$. Additionally in some small regions of Canada such successes were achieved and at present The South Korea plans to build such plant having more greater capacity than France has.

It stands, the method to obtain clean energy has great disadvantage. Specialists on nature and environmental management protect this because of being harmful against the natural floods by creating obstacles for the living organisms, whole ecosystems over the bays. Researchers on technology think to solve and improve this deficiency to persuade ecologists while designing turbines in the tidal lagoon.

Instead of the direct dam developed within the estuary, they suggest to use the innovative technologies' successes for installing artificial lagoons along the coastlines at least $1 \mathrm{~m}$ exceeding maximum rise of the tides.

By such type turbines can be located in the immediate vicinity of the ocean floor, but will not touch on it. The concept is simple and efficient because the highest water flow via the turbine causes the motor to rotate at low tide, too and by flowing back the water makes the turbine rotate in the opposite direction. Finally electricity is generated in both directions of the turbine rotation 4 times a day.

The lagoon location depends on the difference between the tide and tide levels. The energy production expected by this way will be economically much cheaper than obtaining energy from the non traditional fuels such as coal combustion and the environment safety remains under protection by being parallel such power generators developments have been planned in Wales and China.

Such traditional combinations may give the success to the innovative technologies to solve the present ecological and environmental questions. Now some still believe that such power stations can be obstacle for the ship routes. However, the ocean turbines improvement allows to obtain energy independently, by regenerating way without any damage for the vessels on the shipping lane therefore similar warnings are in vane.

In narrow straits generally streams move faster, in this case huge energy is produced by ocean turbines, so this showing proves the method to be the most excellent alternative source instead of nuclear power plants to generate huge electricity and supply energy demand of the populations and industries.

Due to the harmless action of the technology for the ecosystems, such energy source type attracts the attention of the world countries having advanced technology opportunity, industrial cooperation's and environmental companies to generate electricity from clean effective tidal energy.

In this case some question arises: Is it really necessary to save our planet and peoples from the current environmental threats by producing nuclear energy which makes the most inescapable harm to the environment and living organisms?

None of us wants to live in the world having nuclear damage if it supplies you by energy, too. So the present world needs cleaner and safer environment while realizing energy generation methods by using innovative technologies and techniques proven superiorly.

On the base of new existing energy production methods pollution threat and ecosystems destruction should be reduced and solved beforehand.

Amidst alternative energy sources one of the most perspective field if wave energy. According to its own potential, durability, coverage scale wave energy differs from other renewable energy sources with some positive characteristics. Wave energy can be obtained in two directions so as both hydrodynamic and aerodynamic. For comparison $1 \mathrm{MW}$ hydrodynamic wave energy plant is 4-5 times more expensive than the wind energy plant having the same capacity so, its cost consists of 12-14 million $€$. At the same time the wave energy device value is more times cheap than mentioned one. In the course of wave energy application some technical and technological difficulties appear. So, waves distinguish due to their direction, amplitude, phase, speed. In such difficult condition regular working of sea wave device and invariable electricity are not easy but optimal variant is able to be defined on the base of several measurement. Thus and so in any external situations the appropriate construction and working details ought to be acted. Averagely wave amplitude increases more than 10 times after each 40-50 years. Taking into consideration these showings, projecting wave energy device construction should be permanent against the permissible load more than 100 times. There's a great deal of potential for using wave energy in the Caspian Sea coastline, mainly Absheron peninsula shore. In the southern coast of Absheron average annual height for sea wave is $1-2 \mathrm{~m}$ and in the northern coasts that is 1,5-2,5m. Along the Azerbaijan shoreline of the Caspian Sea average annual height of the wave sometimes consists of 8$10 \mathrm{~m}$ [11], [12]. Building and exploitation of devices based on sample construction for this area is advantageous from technical point of view. One of such devices is Wells turbine that having high aerodynamic characteristics, one direction rotation during forward and back wave movement, resistibility in any meteorological situation and being effective energy transformer. All features of the facility are suitable for the natural climate condition on the Caspian Sea. Therefore this makes too great interest in order to apply the plant here. Up today many researches and tests have been done for improving Wells turbine [13], [14]. Thus, to the realized tests and researches mainly on the Northern sea coast so, England, Denmark, Germany and other European countries testing and experimental investigations are being carried out. 


\section{Calculation Method}

The main parameters of Wells turbine 3 disproportionate ratios are to be determined due to the following method:

Theses disproportionate ratios are pressure $\Psi$, curling moment of the device $\Pi$ and efficiency $\eta$ and are defined as [13]:

$$
\Psi=\frac{\Delta p}{\rho_{h} \omega^{2} r_{t}^{2}}
$$

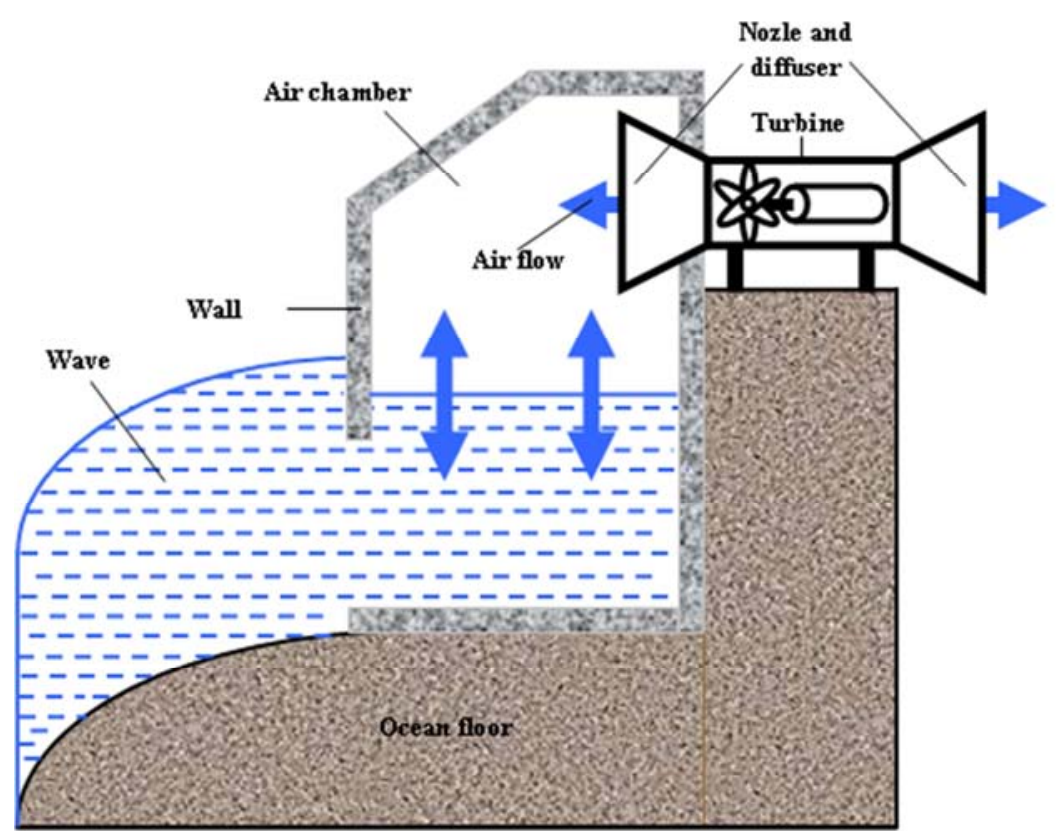

Figure 1. Principal scheme of Wells turbine

$$
\begin{gathered}
\Pi=\frac{T}{\rho_{h} \omega^{2} r_{t}^{5}} \\
\eta=\frac{T \omega}{\Delta p Q}
\end{gathered}
$$

Here $\Delta p$-pressure drop in the turbine; $\rho_{h}$-density of the air; $\omega$ - turbine rotation speed; $r_{t}$ - turbine rotor radius; $T$ - turbine curling moment; $Q$ - capacity constant of the air passing trough the turbine.

Efficiency of pressure drop during Wells turbine action, curling moment and dependence of these showings on the turbine consumption constant has been determined. Taking into consideration maximum, average and minimum indexes of the both pressure changing and curling moment dependences were obtained.

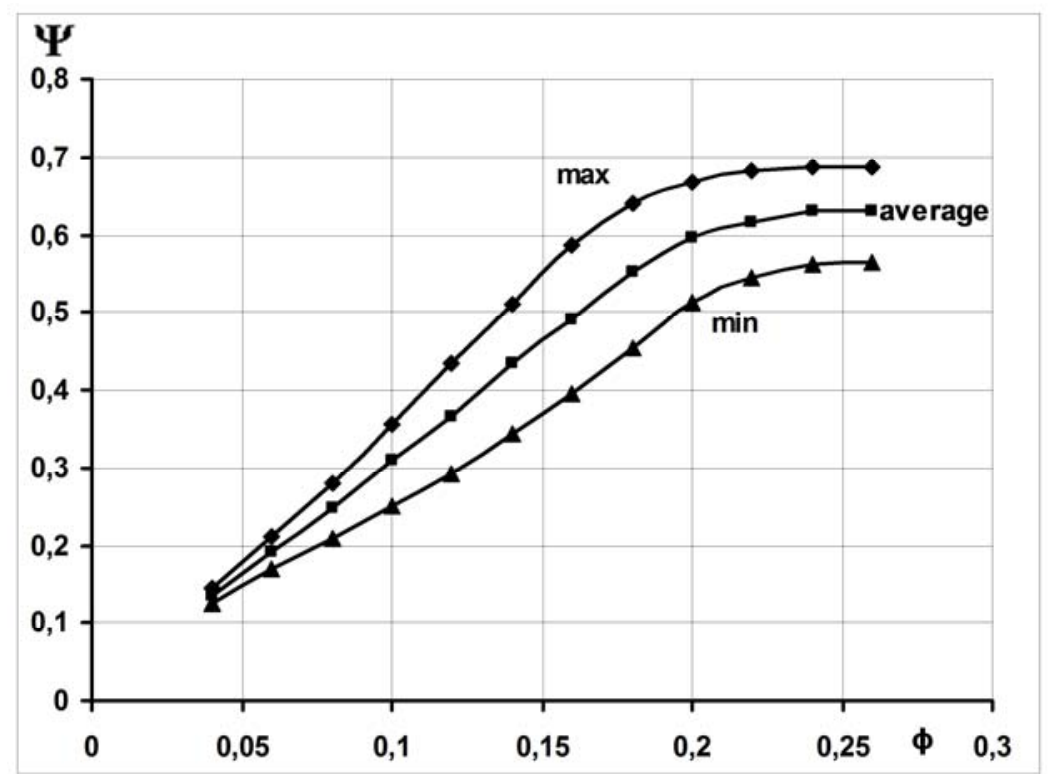

Figure 2. Dependence of pressure changes from coefficient of discharge in Wells turbine. 


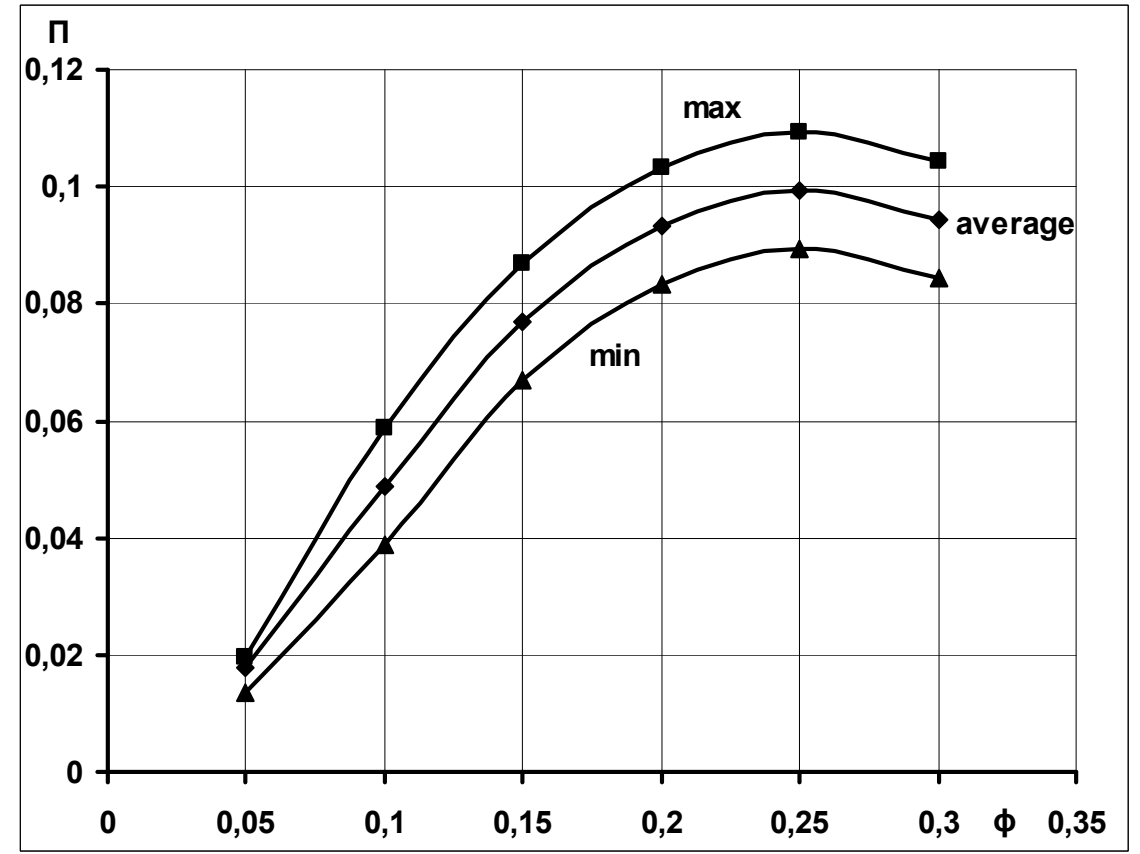

Figure 3. Dependence of torque shaft from coefficient of discharge in Wells turbine.

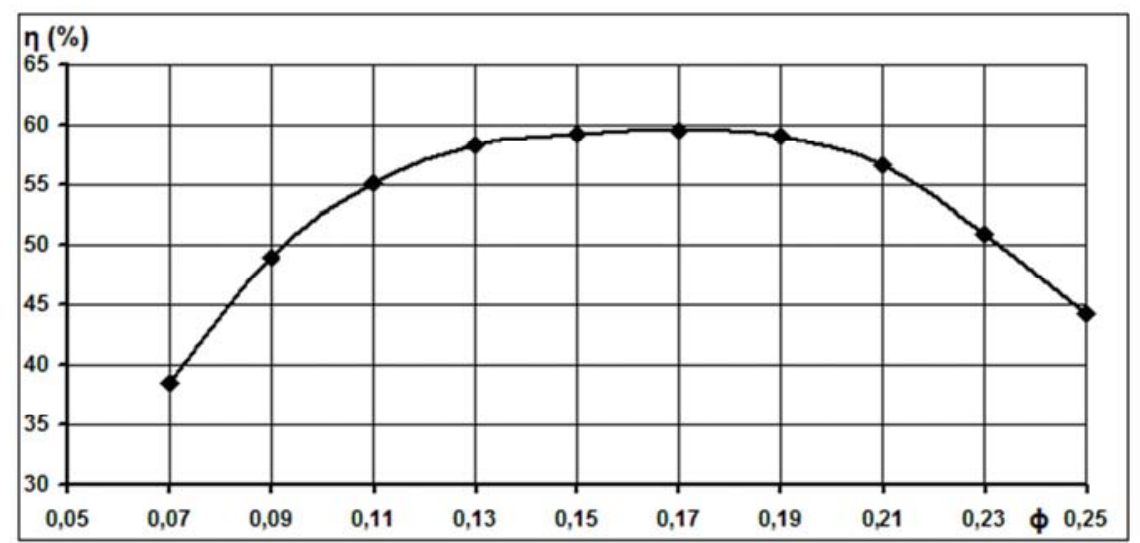

Figure 4. Dependence of efficiency from coefficient of discharge in Wells turbine.

In several natural conditions, depending on none of the season pressure drop in the turbine is difficult to be defined. Naturally stochastic position, so none-stationary regime exists, therefore the average showing is to be taken.

For determining turbine pressure drop the following equation is used [14]:

$$
\Delta p=\frac{\Delta p_{0}}{\rho_{h} \omega^{2} r_{t}^{2}}
$$

Here, $\Delta p_{0}$ - constant pressure drop happing along the turbine.

Expenditure coefficient and suitable curves to this coefficient are defined by the next equation $[15,16]$ :

$$
\phi=\frac{V}{\omega r_{t}}
$$

Here, $V$ - stream speed appearing on the central axe in the turbine is measured by the ratio of the total stream capacity $Q$ speed, cross-section square $A_{t}$ of the circular canal.

$$
V=\frac{Q}{A_{t}}
$$

Due to these calculations, it's possible to say that depending on the air stream speed, pressure drop can be determined.

According to the reference [11] showings dealing with the northern-east coast of Absheron, initially taking into consideration existing technical parameters of Wells turbine with $10 \mathrm{~kW}$ powers, by the purpose of efficiency of the device output strength defining following the above method dependences have been obtained. 


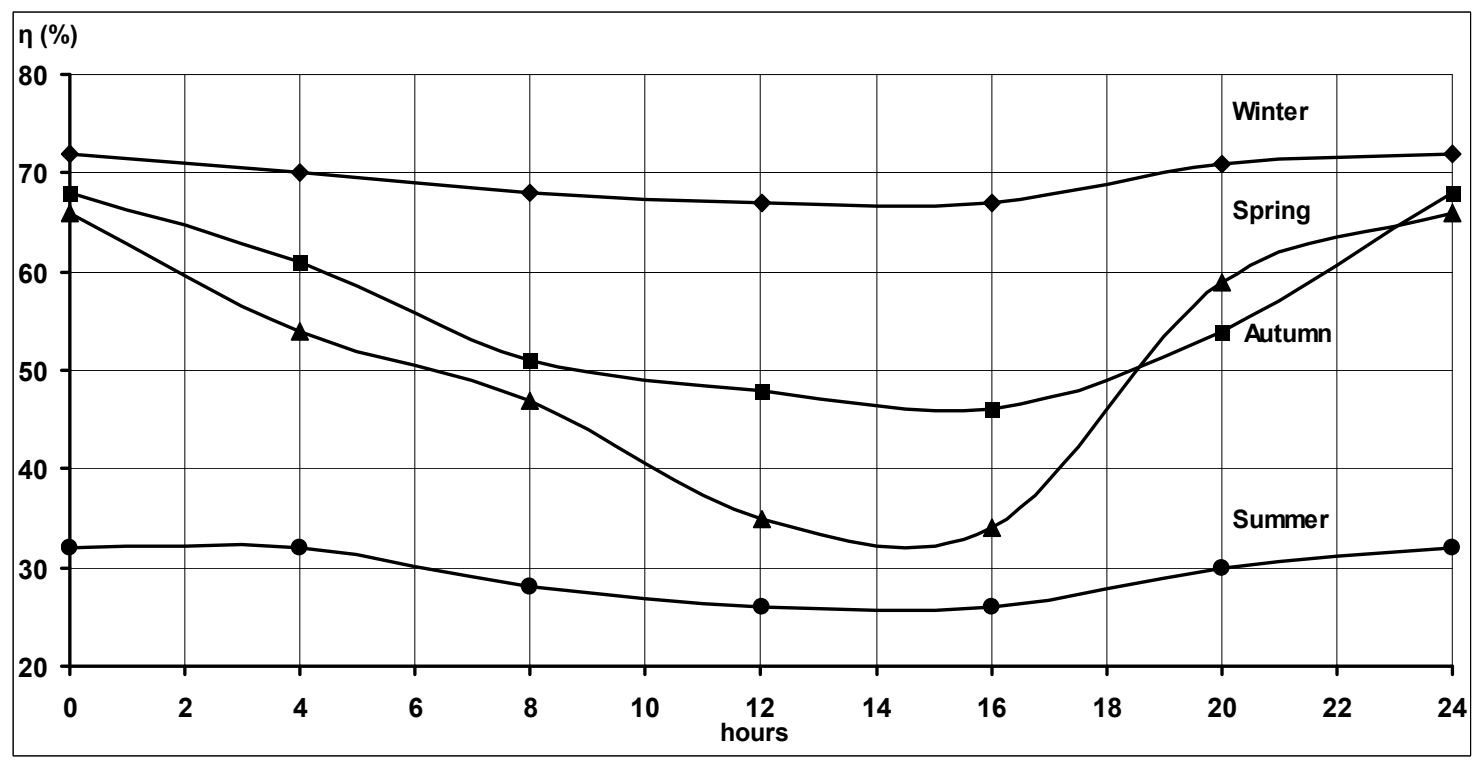

Figure 5. Dependence of efficiency from daily hours of seasons of Wells turbine.

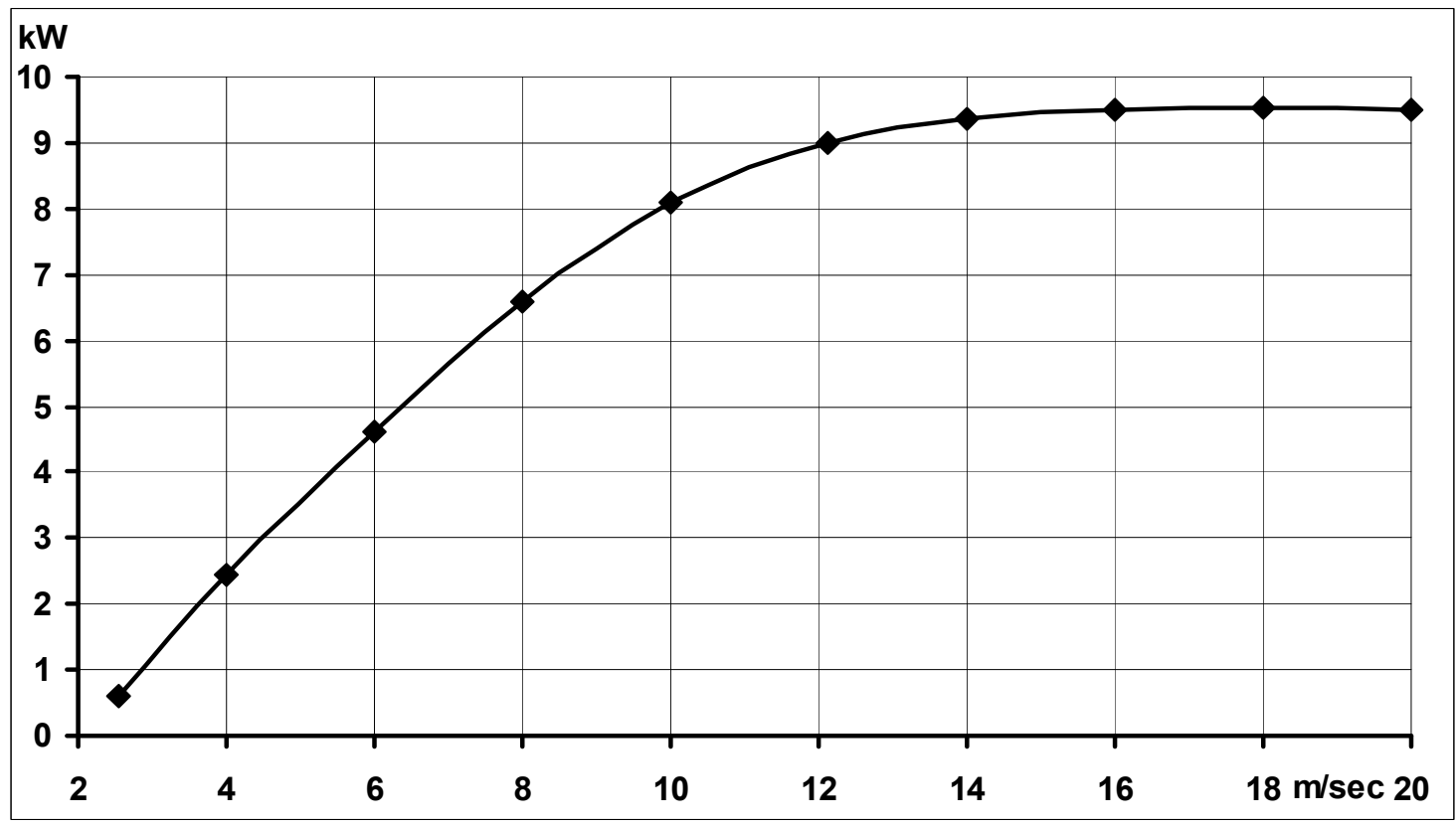

Figure 6. Dependence of power of Wells turbine speed of air flow.

As seen from the figure 5, the most advantage of Wells turbine efficiency occcurs in winter but lest one happens in summer. Autumn and spring seasons' efficiency practically equals.

In comparison with the decreasing windy days amount in spring, strong windy days appear from early autumn efficiency is gradually increases.

As seen from figure 6 depending on the air stream speed happening in nozzle and difusser of Wells turbine, changing curves of the device output strength is shown.

In $0-10 \mathrm{~m} / \mathrm{sec}$ index of the air stream in nozzle and difusser output strength acts probably rectilineel but in 10-20 $\mathrm{m} / \mathrm{sec}$ index it is relatively stable.

\section{Results}

(1) Wells turbine is technical profitable for the Caspian sea condition;

(2) Wells turbine's seasonable theoritical efficiency data has been developed;

(3) Jet, diffuser application in the turbine is acceptable due to wave amplitude and frequency;

(4) For offshore oil and gas platform's energy supply the turbine's technical and economical profits;

(5) Initial power of the energy station with Wells turbines may be consist of $3500 \mathrm{~mW}$. 


\section{Conclusion}

Summerizing the study results, it should be mentioned that the Caspian sea is one of the most windy seas. Therefore the wave potential and the frenquence are great. The strongest storms happen in the sea which occur too many accidents including human-beings loss on the oil-gas platforms. In order to reduce the quantity of the storms density, such kind of wave turbines must be apply at the bottom of the sea.

The fact is that after the final tsunami happened around the Japan coasts which caused Fukushima accident, too, energy engineers decided to apply wave turbines instead of the nuclear power stations. At the same time for descrease the wave speed and capacity forming the tsunami they planned $t$ built 30000 such turbines to supply electricity demand, too.

The highest potential of the Caspian Sea exists on the northern-east coast and profitable for Wells turbine by ecological, technical and economical point view. To provide the secure work regime in the ooshore oil-gas sector the presented turbines' usage is much more necessary. Initially as the pilot project devices with $10-20 \mathrm{~kW}$ power may be applied in this area.

\section{References}

[1] Astariz S, Iglesias G. The economics of wave energy: A review. Renewable Sustainable Energy Review, 2015; 45, pp 397-408.

[2] Soleimani K, Ketabdari MJ, Khorasani F. Feasibility study on tidal and wave energy conversion in Iranian seas. Sustain Energy Technol Assessments 2015; 11, pp 77-86.

[3] Vicinanza, D., P. Contestabile, and V. Ferrante, Wave energy potential in the north-west of Sardinia (Italy). Renewable Energy, 2013. 50: pp. 506-521.

[4] Bilgili M, Ozbek A, Sahin B, Kahraman A. An overview of renewable electric power capacity and progress in new technologies in the world. Renewable Sustainable Energy Review, 2015; 49, pp 323-334.
[5] Lejerskog E, Bostrom C, Hai L, Waters R, Leijon M. Experimental results on power absorption from a wave energy converter at the Lysekil wave energy research site. Renewable Energy, 2015; 77, pp 9-14.

[6] Lopez I, Andreu J, Ceballos S, de Alegría IM, Kortabarria I. Review of wave energy technologies and the necessary power-equipment. Renewable Sustainable Energy Review, 2013; 27, pp 413-434.

[7] Kamranzad B, Etemad Shahidi A, Chegini V. Sustainability of wave energy resources in southern Caspian Sea. Energy, 2016; 97, pp 549-559.

[8] Saket, A. and A. Etemad-Shahidi, Wave energy potential along the northern coasts of the Gulf of Oman, Iran. Renewable Energy, 2012. 40(1): pp. 90-97.

[9] Liberti, L., A. Carillo, and G. Sannino, Wave energy resource assessment in the Mediterranean, the Italian perspective. Renewable Energy, 2013. 50: pp. 938-949.

[10] Gholamreza Amirinia, Bahareh Kamranzad, Somayeh Mafi. Wind and wave energy potential in southern Caspian Sea using uncertainty analysis. Energy, 2016; 88, pp 1-14.

[11] Azerbaijan National Atlas, 2014.

[12] In-Depth Review of the Energy Efficiency Policy of Azerbaijan. Energy charger secretariat. 2013, pp. 114.

[13] Torresi M., Camporeale S. M., Strippoli P. D., and Pascazio G. Accurate numerical simulation of a high solidity Wells turbine. Renewable Energy, 33: 735-747, 2008.

[14] Dorrell D. G. and Hsieh M.-F., "Segmented small oscillating water columns using in-line Savonius rotors"// ISOPE Conference 2007, Portugal, Lisbon, 1-6 July, 2007.

[15] Dhanasekaran T. S. and Govardhan M. Computational analysis of performance and flow investigation on Wells turbine for wave energy conversion// Renewable. Energy, 30, 2129-2147, 2005.

[16] Folley M., Curran R., Whittaker T. Comparison of LIMPET contra-rotating wells turbine with theoretical and model test predictions// Ocean Engineering, 33 (2006), 8-9, 1056-106. 